\title{
Multi-Systemic Model of Juvenile Justice Reform: Adopting the Missouri Model in California
}

\author{
By Ana Gioconda Jara
}

The juvenile justice system serves a marginalized and vulnerable population of high-risk youth who have been convicted of committing crimes. This system uses substantial state budgets for housing, staffing, and programming for the youth offender population. As states look to reform their juvenile justice systems, one specific model they should consider implementing is the Multi-Systemic Treatment (MST) approach, an intensive residentialbased intervention for chronic, violent, or substance abusing juvenile offenders, ages 12 to 18, that uses trained therapists to work in small facilities with the youth and his or her family. This study examines the Missouri Model, an MST program that was successfully implemented statewide. This paper provides a cost-benefit analysis of a proposed transformation of California's juvenile justice system by implementing the MST model at a statewide level.

\section{Juvenile Justice in California}

The juvenile justice system in California has two ultimate goals: public safety and the treatment and rehabilitation of juvenile offenders (Legislative Analyst's Office 1995). As research and advocacy have been focused on reform for both adult and juvenile justice systems, current approaches have been questioned and evaluated for their efficiency and outcomes. Entering this system puts these youth on a trajectory that, for many, includes a higher risk of adult arrest and criminality (Mendel 2010). Evaluation research indicates that the current juvenile justice system is not effective in rehabilitating youth and may actually be causing long-term physical, emotional, and mental harm (Feld 1999).

Within the juvenile justice field, youth are presented in three basic risk categories: low, moderate, and high. These categories are based on various risk factors that include past crimes, parent involvement, antisocial behaviors, and family criminality (Latessa and Lovins 2010). There are two fundamental approaches to juvenile justice reform. The first focuses on prevention: screening out those youth who are low-risk offenders and diverting them toward a community-based program, such as detention alternatives including youth court or life-skill training programs (Lipsey et al. 2010). The second method of reform focuses on intervention: transforming the facilities to which high-risk youth offenders are sent (Lipsey et al. 2010). This is the crux of the policy examined here-to transform the facilities and method by which this population of high-risk youth offenders are treated and rehabilitated.

Currently, California has four youth correctional facilities statewide, three of which are male only and one facility that is co-ed. Each facility houses between 387 and 700 youth who are considered to be high-risk, and these facilities are, in most cases, far from residents' homes. As of December 2010, 1,118 youth offenders were being detained in youth correctional facilities in California (CDCR 2010a). This cost-benefit analysis will examine the proposed policy intervention of 
shutting down the four current large facilities and replacing them with 31 small, dorm-style residential facilities statewide that use the MST approach, modeled after the program used in Missouri.

\section{Overview of This Study}

The first part of this paper details the general assumptions made in the base case analysis; the second part describes the values and methodologies used to calculate each cost and benefit; the third part tests the strength of the findings using sensitivity analysis; the fourth part informs further considerations for policymakers; and the fifth part offers a summary of the policy and recommendations for moving forward with implementation.

All California residents have standing, so from this point they will be referred to as California taxpayers. Under the base case analysis, the policy intervention results in net benefits of $\$ 5.9$ billion over five years. The best-case scenario results in net benefits of $\$ 14.8$ billion. The worst-case scenario analysis results in net benefits of $\$ 1.5$ billion.

\section{Multi-Systemic Treatment (MST)}

According to a report by the Washington State Institute for Public Policy, Multi-Systemic Treatment (MST) has a relatively high rate of return of $\$ 28.33$ for every dollar spent when compared to other popular crime prevention programs (WSIPP 2001). The MST design is based on several factors, including an emphasis on addressing the causes of delinquency, incorporating family engagement in the treatment plan and execution, offering life skills training, and providing group counseling. "The treatment services are delivered in the youth's home, school and community settings, with a strong focus on treatment adherence and program fidelity" (WSIPP 2001, 117).

The policy intervention proposed in this analysis would use the MST design for the high-risk youth offender population of California, and it calls for the cre- ation of 31 facilities. These facilities would include 24-hour supervision of youth offenders and would provide specialized services including residential, nutritional, educational, recreational, medical, workforce development, and mental health services.

A central component of MST is the paradigm shift from simply housing youth in detention centers to focusing on reintegrating youth into their communities from the very first day of arrest. These high-risk facilities would serve the most serious and chronic young offenders as defined by the corrections system.

The MST model of Missouri serves as a good example for this study because it was part of a larger state reform, and it was implemented for the entire state, as this analysis proposes for California (Vestal 2008). The MST design prepares youth for community reintegration within a home-like environment through the principles of positive youth development and guided peer interaction to promote transformation of youth and their behavior. Key components of the program include (The Annie E. Casey Foundation 2010):

-A team approach to comprehensive treatment planning;

-A four-phase behavioral level system to track progress and determine each young person's readiness for release;

- Group counseling (including substance abuse counseling);

-Educational services and vocational/employment training and readiness.

\section{General Assumptions of the Cost- Benefit Analysis}

The analytical tool of cost-benefit analysis provides a comprehensive lens through which to evaluate a policy's social impacts and overall efficiency. The advantages to using this tool are: 1) it helps to compare a current policy or program and its efficiency with an alternative; 2) it helps to display a broad long-term view of societal benefits including savings, future 
earnings, and avoided costs; and 3) it allows policy makers to make an informed decision and see the perspective of those who carry the brunt of both benefits and costs (Cellini 2012). A key component of cost-benefit analysis is that it holistically looks at a policy intervention, and it incorporates both societal costs and benefits using estimated numbers for comparison.

The calculated costs and benefits of the policy intervention are based on five basic assumptions. First, for purposes of calculation, this analysis assumed that the policy would start in 2013 and calculates costs and benefits for the first five years of implementation. The second assumption is that the benefits of the MST model will yield results in California at the same rate as they occurred in Missouri. Missouri uses a capacity of 36 beds per facility, while other states that have adopted the MST model have ranged from 30 to 60 beds per facility. In order to stay true to the model used in Missouri and to better facilitate the intimate and controlled setting for which this evidence-based best practice model is known (Lipsey et al. 2010), this study keeps the 36 beds per facility ratio.

The third assumption is that there is a uniform distribution of juvenile crime rates across the state of California. Available data is from the state level and does not disaggregate information by county. This study assumed that any potential differences among counties will not have a substantial impact on crime rate calculations. Assuming uniform distribution of crime rates allows for a statewide perspective instead of targeting facility placement based on county crime rate. This uniform distribution assumption is important because the core of the calculations is based on the projected percentage change in recidivism in the statewide population of high-risk youth offenders. This value will be used to forecast impact.

The fourth assumption concerns recidivism rates. Recidivism refers to the number of youth that are re-incarcerated in juvenile or adult correctional facili- ties within three years of release from a juvenile facility. Almost one in four (24.3 percent) of the youth under the Missouri model recidivate (The Annie E. Casey Foundation 2010). By comparison, an evaluation report published by the California Department of Corrections and Rehabilitation found that " $56.5 \%$ of youth returned to state level incarceration within three years of release" (CDCR 2010b, v). If the study can assume that the same results would be obtained by replicating the Missouri Model in California, then the benefits would be found in the decrease in recidivism rates. The reduction of 32 percentage points of recidivism is the assumed projected benefit.

Lastly, it is assumed that any costs accrued by possible negative economic impacts in terms of lost jobs in the communities where the four facilities currently exist are equal to the benefits accrued by the new jobs created in the communities where the 31 facilities are proposed. Thus, the net benefits of the "local economy" factor are zero.

\section{Calculation Timeframes}

This analysis looked at three categories of benefits with projections over various periods of time. The study looked at costs in the first year and benefits in the fifth year, as well as total costs and benefits over five years. The advantage of using cost-benefit analysis is that it allows us to compare dollar amounts in today's value regardless of when they are spent or gained, therefore allowing us to compare costs more closely. The first benefit category examined is recidivism, projected to take effect three years after youth are released from the California Department of Corrections and Rehabilitation. This study assumed that year one is the initial implementation, year two the design takes effect, but benefits are not recognized until year five of the MST model implementation because of the three years needed to measure recidivism. The second category of benefit is the difference between the 
status quo and expected benefits in terms of high school graduation rates that begin to be accounted for one year after implementation. The final category is related to the change in reported sexual assaults within the facilities; this rate was measured beginning one year after implementation.

This analysis measured these benefits using a social discount rate. A social discount rate is a way to compare dollar values from different time periods. Discounting is used to transform future value into present-day value in order to more effectively compare dollar amounts. All of the cost-benefit analysis projections were based on a social discount rate of 5 percent, which is one of the accepted measures in the criminal justice field and is used by the Urban Institute for their criminal justice cost-benefit analysis (CBCK 2013). Costs were assumed to be constant and do not vary across years or crime categories.

\section{Costs}

The policy intervention of implementing the MST design in the state of California is estimated to cost $\$ 1.1$ billion over five years after discounting to the present value.

\section{Costs to California Taxpayers}

There are two main sources of costs related to this intervention. First, the capital costs include the land for facilities as well as the construction costs of the actual facilities. Second, the operational costs include costs related to the ongoing running of the facility and include personnel costs in salaries.

In order to project how many facilities would be needed in California if this policy were to be adopted, the total population of California high-risk youth offenders of 1,118 (CDCR 2010a) was divided by the number of beds that the Missouri Model includes per facility (36), resulting in 31 facilities. After establishing a "per facility" cost, that figure is multiplied by the number of facilities (31) in order to find the total cost for state implementation.

Next, this study calculated a cost per facility. This step begins with a calculation of the costs related to the purchase of land. The study assumed that the preconstruction costs are negligible, meaning that there would be no additional cost associated with excavating any land or demolishing any buildings. In order to stay consistent with a uniform distribution across the state, the average cost of land was estimated using the online real estate source LandWatch, and searching for California land parcels between 11 to 12 acres. The range was calculated at $\$ 11,000$ to $\$ 500,000$ per acre (LandWatch 2013), which is an average of $\$ 255,500$ per acre. Using an average as opposed to a true land cost by area could lead to a potential under or over calculation because the state of California has a wide range of land costs. This issue will be addressed in the sensitivity analysis.

In order to determine how many acres would be needed per facility, information on the Missouri Model detention centers was first consulted; however, details on the size of the facilities were not available. Nevertheless, information about facility size was available for the program used by the Department of Youth Corrections in Washington, DC. This program, named New Beginnings, is fashioned after the Missouri Model and uses the MST design (DCDYRSF 2012). The New Beginnings Youth Development Center is a 6o-bed (DCDYRSF 2012) facility that occupies 15 acres in Laurel, Maryland (AECOM Construction Services 2012). This center is complete with dorm-style rooms, educational rooms, a gymnasium, and a warehouse.

The basis for the proposed size of the California sites will be 75 percent of the acreage used by Washington, DC in order to give a closer estimate for the area needed for a 36-bed site. It is important to note that 75 percent of 60 equals 45 beds, 
and therefore this calculation could imply an overestimate of costs since the facility will be large enough to accommodate nine extra youth. Multiplying 11.25 needed acres (75 percent of the 15 acres used for the New Beginnings Youth Development Center) by the estimated cost of $\$ 255,500$ per acre results in the capital cost of land being $\$ 2.9$ million per facility.

The square footage reported for the New Beginnings Youth Development Center, 93,000 square feet, was used to determine construction costs for the California facilities (AECOM Construction Services 2012). Again, the study used 75 percent of the size used in New Beginnings, resulting in a total of 69,750 square feet needed per facility. California prison construction costs provided by the Reed Construction Company estimated the cost at \$241 per square foot (Reed Construction 2013). The data did not specify costs for juvenile prisons, but the study assumed that costs for juvenile prisons would be the same as the costs per square foot of adult prisons. Multiplying \$241 (per square foot) by 69,750 square feet resulted in construction costs of $\$ 16.8$ million per facility. Adding the \$2.9 million land cost to this amount results in $\$ 19.7$ million per facility in capital cost. Taking the value of $\$ 19.7$ million per facility and multiplying it by 31 (total number of facilities needed) provides a grand total of $\$ 610$ million in capital cost for the entire project. Costs are broken down in Table 1.

The next expense category is facility operating costs. Based on the number of youth in each team or cohort, the Missouri Model reports a 12:1 ratio for therapists (The Annie E. Casey Foundation 2010); this ratio means that applying the MST model in California would require three therapists per facility. The Missouri Model itself does not specify any other staff ratio so a replicated program was used. The Missouri Model's replication in Santa Clara County uses a 6:1 youth-to-staff ratio (Krisberg 2009), which translates to a need for six teachers, six field workers, six officers, and six case managers per facility. In addition, it is assumed that one administrator per facility would be needed.

Salaries for staff were calculated using data from the Bureau of Labor Statistics (BLS). The average yearly salary for a California secondary teacher is $\$ 65,620$ (BLS 2011). The 2010 median yearly salary for a correctional officer is $\$ 39,020$ (BLS 2012b); for a field social worker, using the classification of social service specialist is $\$ 39,250$ (BLS 2012f); and for a case manager, using the classification of correctional treatment specialist is $\$ 47,200$ (BLS 2012c). Multiplying these median salaries by six (for each staff member in each category) provides a per-facility operating cost of staff salaries. Since there was no avail-

Table 1: Base Case Capital Costs for Year One of Implementation

\begin{tabular}{|l|c|c|c|}
\hline & $\begin{array}{c}\text { Description of Cost Per } \\
\text { Facility }\end{array}$ & Each Item & Total Per Facility \\
\hline & Land cost per acre & $\$ 255,500$ & \\
\hline & Number of acres needed & 11.25 & $\$ 2,874,375$ \\
\hline & $\begin{array}{c}\text { Construction cost per } \\
\text { square foot }\end{array}$ & $\$ 241$ & \\
\hline & Square feet needed & 69,750 & $\$ 16,809,750$ \\
\hline & Total Cost (per facility) & & $\mathbf{\$ 1 9 , 6 8 4 , 1 2 5}$ \\
\hline Total Capital Cost & $\begin{array}{c}\text { Total cost per } \\
\text { facility x31 facilities }\end{array}$ & & $\mathbf{\$ 6 1 0 , 2 0 7 , 8 7 5}$ \\
\hline
\end{tabular}

Note: Author's calculations. 
able data for therapists, the median yearly salary for a psychologist, $\$ 68,640$ (BLS 2012e), was used for therapist salary. This result was multiplied by three and added to per facility operating cost. BLS does not provide information on correctional facility administrators' salaries, so this study used the 2010 median yearly salary for a top executive, $\$ 101,250$ (BLS 2013b). By these calculations, the total cost for staff salaries is $\$ 2,453,710$ per facility per year.

The next set of calculations focused on benefits, and they were also taken from BLS using values for government employees. The average cost of monthly health insurance is 12 percent of total compensation for state and local government workers (BLS 2012d). Insurance costs were calculated by taking the total cost of staff salary $(\$ 2,453,710)$ and multiplying it by 0.12 , obtaining a total of $\$ 294,446$. Pension benefits are estimated at 8.8 percent of total compensation (BLS 2012d), and resulted in a cost of $\$ 212,927$ per year. The last calculation made using total salary costs is the legal requirements of employers to pay at least 6.1 percent of total compensation (BLS 2012d) for Social Security, state and federal unemployment insurance, and Medicare, which resulted in costs of $\$ 149,677$. There is an additional $\$ 1$ million per facility budgeted for office maintenance (including supplies) and support staff including administrative assistants, janitors, and nurses. After adding the cost of legal requirements, health insurance, and pension benefits to total staff salary, cost totaled \$3.1 million per year per facility. Included in the overall operating cost per facility is also a small budget for the family participation program to buy laptops and Skype credit, as well as mileage reimbursement for the field worker $(\$ 11,000)$ for each facility.

\section{Additional Costs Related to Staff}

While salaries include time used for staff training, the cost-benefit analysis used in this study has the ability to monetize additional effort needed to change institutional culture. This calculation applies an hourly rate for each staff impacted by the change. This cost will cover the time that administrators, officers, and therapists will need for training in order to transition the MST design into effective juvenile justice programming. It was assumed that some staff will be resistant to the treatment change for various reasons: disagreement in ideology, a lack of training, or comfort with the status quo. The costs accumulated in this section represent the extra time and challenges that reforming an institution requires. This cost, although monetized, is not salary increases or overtime, but is the personal cost to administrators, officers, and therapists measured in their time value based on their current salaries. The cost is not extra compensation for these employees; it is used as a way to monetize certain social costs related to implementing a new program. The total calculated operating cost of running the MST design in California was \$97 million. Operating costs are detailed in Table 2.

\section{Other Costs}

In the current system, youth are locked away in detention centers without access to their schools, communities, or work. This proposed implementation of the MST design would change the youth offenders' experience inside those centers, not the time spent in them. The additional time that families would be expected to invest while participating in the MST design is thus considered a negligible benefit. Also, the costs that would be incurred to transport the youth from present to future locations were not included in the analysis, as these costs are already allocated in the current budget because California Department of Corrections and Rehabilitation has its own fleet of buses.

There is one additional cost that is worth mentioning, which the literature did not consider significant: property devaluation. Research in three other states examining prison impacts on property value found no devaluation of property after a 
Multi-Systemic Model of Juvenile Justice Reform

Table 2: Base Case Operating Costs for Year One of Implementation

\begin{tabular}{|l|l|c|c|}
\hline Type of Cost & Description of Cost Per Facility & Each Position & Total/Facility \\
\hline Operating Cost & & & \\
\hline & Salaried psychologists (x3) & $\$ 68,640$ & $\$ 205,920$ \\
\hline & Salaried teacher (x6) & $\$ 65,620$ & $\$ 393,720$ \\
\hline & Salaried correctional officers (x6) & $\$ 39,020$ & $\$ 234,120$ \\
\hline & Salaried field worker (x6) & $\$ 39,250$ & $\$ 235,500$ \\
\hline & $\begin{array}{l}\text { Salaried case manager/ } \\
\text { coordinator (x6) }\end{array}$ & $\$ 47,200$ & $\$ 283,200$ \\
\hline & Salaried administrators (x1) & $\$ 101,250$ & $\$ 101,250$ \\
\hline & $\begin{array}{l}\text { Support staff } \\
\text { (janitor, nurse, administrators, etc.) }\end{array}$ & & $\$ 1,000,000$ \\
\hline & Total cost of staff per year & & $\$ 2,453,710$ \\
\hline & Insurance benefits per year & & $\$ 294,446$ \\
\hline & $\begin{array}{l}\text { Pension Legally required (Social } \\
\text { Security, Medicare, unemploy- } \\
\text { ment) benefits }\end{array}$ & & $\$ 215,927$ \\
\hline & $\begin{array}{l}\text { Legally required (Social Secu- } \\
\text { rity, Medicare, unemployment) }\end{array}$ & & $\$ 149,677$ \\
\hline Total Operating & $\begin{array}{l}\text { Family participation and field } \\
\text { worker mileage reimbursement }\end{array}$ & & $\$ \mathbf{6 , 8 6 7 , 5 6 0}$ \\
\hline & Staff support costs & & $\$ 32,730$ \\
\hline & Total per facility & & $\$ 3,124,760$ \\
\hline
\end{tabular}

Note: Author's calculations.

prison was built (Donner 2012). Since the proposed policy intervention would actually move away from a prison system to smaller facilities, it was assumed that the change would have no impact on property values.

The total costs of the state policy intervention of using the MST design for California's high-risk youth offender population, including capital and operating costs for year one, were $\$ 707$ million. The total net present value of costs over five years was $\$ 1.1$ billion. Note that a large portion of the costs are in year one, so they are not socially discounted as they are measured in current dollar amounts.

\section{Benefits}

This policy intervention was esti- mated to benefit three groups: California taxpayers, youth offenders, and future potential crime victims. The benefits are expected to total $\$ 7$ billion over five years after discounting to the net present value. The benefits are summarized in Table 3 for the fifth year and for the program over five years of implementation. There are three categories of benefits that are gained from implementing the MST design in California. The first is the avoided costs linked to the 32 percentage-point reduction in recidivism rate as detailed above.

Second is graduation rates, which are viewed as a benefit of adopting this model because graduation has a long-term impact on the lives of youth. Higher graduation rates are connected to increased fu- 
ture earnings for each of those graduated youth. Traditional incarceration models have a negative impact on youth education (Justice Policy Institute 2006), while the MST model is designed to work "with families to address underlying causes of delinquency, such as improving families' communication, increasing the youth's positive peers and recreational activities, and improving school or vocational performance" (Act 4 Juvenile Justice 2009, 2). Improving school performance leads to higher completion of school goals like graduation. The increased earnings will be counted as marginal tax revenue for the state of California. The benefits of increased graduation rates will begin to be counted one year after implementation, and will ultimately be measured as increased earnings and marginal tax revenue.

The last category of benefit is avoided sexual assaults that directly impact youth offenders. One of the complaints and concerns that many advocates discuss is the conditions of confinement and its ultimate harm on the high-risk youth detained in facilities (The Annie E. Casey Foundation 2011). Lawsuits around sexual assault incidents have driven a large part of the reform efforts in juvenile justice, particularly in California (Justice Policy Institute 2009). The smaller cohort-style living of the MST design lends itself to a safer environment for the youth offenders themselves and is associated with a lower rate of violent incidents for both the youth and staff within the facility (The Annie E. Casey Foundation 2010).

\section{Benefits to California Taxpayers}

The bulk of the taxpayers' benefits come from the avoided costs of incarceration tied to lower recidivism rates, which are not measured until year five. According to the Justice Policy Institute, under the current system, it costs an average of $\$ 67.51$ to house one youth per day in a California facility. Multiplying the Justice Policy Institute's calculation of
$\$ 67.51$ by 358 youth projected to not recidivate (number obtained by multiplying 32 percent by the 1,118 youth currently in California facilities, according to the California Department of Corrections and Rehabilitation 2010) provides a total savings of $\$ 24,168$ per day. Multiplying that figure by 365 days per year results in the total savings of $\$ 8.8$ million per year. The net present value of this amount is $\$ 8.4$ million. For comparison, the sensitivity analysis included a broader range of national daily confinement costs per youth.

Benefits associated with avoided costs tied to fewer re-arrests are much smaller, but enough to be included in the analysis. The state of California does not have public records of costs or data associated with juvenile-specific arrests and prosecutions. The annual budget (including court expenditures, law enforcement, public defenders, and district attorneys) of the California Department of Corrections is $\$ 19.9$ million (California Department of Justice 2009). If the MST model is adopted, and the assumed decrease in recidivism materializes, it is logical to assume that the costs associated with those arrests will be avoided. As the California Department of Corrections and Rehabilitation does not disaggregate information on youth, the calculations are complex. This study began with 10 percent decrease in arrest rates, which was then multiplied to include the estimated 32 percentage point decrease in recidivism. To calculate the avoided court costs due to the drop in recidivism, this study took 10 percent of the original 1,118 high-risk youth offender population resulting in 112 youth. The study used 10 percent as an estimate to calculate as the base for measurement of court costs. That number (112) was divided into the total California corrections population, which resulted in an estimated .1 percent of the entire California corrections population. In order to calculate the avoided costs for every 112 people, the total California corrections budget of $\$ 19.9$ million was multiplied by .1 percent, 
resulting in $\$ 1,989$ for 112 avoided youth arrests. Next, it was necessary to multiply 112 by 3.2 in order to get the desired 358 total youth that would not be re-arrested as a result of a decrease in recidivism. Taking the amount $(\$ 1,989)$ and multiplying it by 3.2 resulted in a total of $\$ 6,365$ saved through avoided arrest costs per year. The net present value is $\$ 6,061$ for benefits gained from arrests avoided.

The last benefit to California taxpayers are the returns or taxes that come from the increased future earnings of the estimated youth offenders who will graduate from high school as a result of this policy. The California Department of Corrections and Rehabilitation does not publish graduation rates of youth offenders, so this analysis used information from the National Evaluation and Technical Assistance Center for the Education of Children and Youth Who Are Neglected, Delinquent, or At-Risk (NDTAC). From 2010 to 2011, the national high school graduation or equivalent rate for youth in detention, corrections, or neglect institutions for ages 16 to 21 was 12.8 percent (NDTAC, n.d.(c)). By comparing the average youth-in-corrections high school graduation or equivalent rate (NDTAC n.d.(a)) of California (18.3 percent) to that in Missouri (30 percent) (NDTAC n.d.(b)), this analysis found an 11.7 percentage point improvement potentially attributable to MST. This 11.7 percentage point increase was monetized by calculating the increase in future earnings related to having completed high school (or equivalent). In order to project how much future earning would be gained if this policy were to be adopted, the national average annual salary difference between a high school graduate and non-graduate of $\$ 10,192$ (BLS 2013a) was multiplied by the assumed average number of years able to work (40) resulting in $\$ 407,680$ per youth. This product $(\$ 407,680)$ was then multiplied by the number of youth the 11.7 percentage point increase in graduation rate would produce (131) and the result was $\$ 53,406,080$ in total future earnings for the youths impacted by this change over their lifetimes.

The last estimated benefit to California taxpayers was to multiply the total future earnings $(\$ 53,406,080)$ by the California marginal tax rate of 6 percent, resulting in a net benefit of $\$ 3,204,365$ of total taxes paid to the state by the future earnings of these youth per year. This benefit was based on the assumption that these youth will be spending their future earnings in the state of California. This study applied a marginal tax rate of 6 percent because it looked at high school graduates and non-graduates, assuming no college in either population. These two groups are likely to be low-income and will therefore pay this tax rate. There is an assumption that youth offenders will contribute to federal taxes as well, but this study was only concerned with the benefits directly attributable to California.

\section{Benefits to Youth Offenders}

Youth offenders stand to benefit greatly from the implementation of the MST design in both increased future earnings and avoided sexual assaults. The biggest benefits come from increased future earnings tied to an increase in high school graduation rates. Using the expected 11.7 percentage point increase in high school graduation rates among high-risk offenders who are currently incarcerated, this study calculated their increase in future earnings, using the data presented above, to be $\$ 53,406,080$ over their lifetime. The net present value total of increased future earnings is $\$ 1$ billion and begins to be counted in the second year of implementation.

Another benefit to youth offenders is the change in facility culture and the increased safety. According to the Missouri Model evaluation, 2 percent of the population in the Missouri facilities reported being victims of sexual assault, defined as forced sexual contact (The Annie E. Casey Foundation 2010). California does not publish the number of sexual assaults re- 
ported in the current facilities so this study used the national rate of sexual reporting. The Center for Children's Law and Policy published a fact sheet in 2010 to understand the report by the Bureau of Justice Statistics stating that the national average of reported sexual victimization within a juvenile facility is $\mathbf{1 2 . 1}$ percent (Center for Children's Law and Policy 2010). This study assumed this national rate holds for California, so the difference was approximately 10 percent.

According to the Cost Benefit Knowledge Bank, an avoided sexual assault is valued at $\$ 205,085$, an amount that includes both tangible and intangible costs (CBKB 2012). Taking the expected 10 percent reduction in sexual assaults in facilities as a result of the policy implementation, this analysis assumed that an estimated 112 sexual assaults will be prevented every year after the MST design implementation, and they begin to be calculated into the total benefits in year two of implementation. Multiplying the monetary value of avoided assaults $(\$ 205,085)$ with the number of assaults avoided (112) resulted in a total of $\$ 22.9$ million saved in enhanced safety; the net present value is $\$ 21.8$ million.

\section{Benefits to Potential Future Crime Victims}

The population that experiences the largest benefit from the policy change is potential future crime victims. This finding is important because the goal of the California Corrections Department is first and foremost "to protect the public from criminal activity" (CDCR 2013a). The measurement of benefits in terms of avoided costs includes both tangible and intangible costs to a victim. Estimating a dollar amount related to victimization is complex, but this study took the values described by the Cost-Benefit Knowledge Bank for Criminal Justice.

Data from the juvenile division of the California Department of Corrections and Rehabilitation indicates that 32.4 percent of all youth incarcerated were con- victed of robberies. The number of youth currently convicted of robbery in California was estimated by multiplying the percentage of robberies (32.4 percent) by the total population of current high-risk youth offenders $(1,118)$, resulting in 360 . This study then multiplied that number (360) by 0.32 to estimate the number of prevented robberies, which resulted in 116. Multiplying this number by the average costs associated with a robbery, $\$ 24,211$ (CBKB 2012), produced $\$ 2.8$ million in benefits due to costs of robberies avoided. The net present value is \$2.6 million, which will not be counted until year five because, again, it was tied to the year four measurement of recidivism. The study continued this calculation process for homicides, assaults, and forcible rapes because those are the most severe crimes, and they are connected to this population of high-risk violent youth offenders. The benefits are summarized in Table 3 for year five of implementation as well as total benefits for five years.

\section{Net Benefits}

Subtracting total costs from total benefits, this policy intervention yields net benefits of $\$ 5.8$ billion over five years as detailed in Table 4. While there are many assumptions used in the calculation, the result suggests that the policy should be adopted to improve efficiency. The next step was to test the results with a sensitivity analysis.

\section{Sensitivity Analysis}

A sensitivity analysis tries to answer the question of whether the bottom line net benefits would be changed and to what degree they would change using different values in the calculations. The majority of values in this analysis were estimates based on a range of assumptions. Although one can never measure the exact impact of a proposed policy prior to implementation, it is possible to test the sensitivity of the analysis to several important value assumptions. In addition to testing 
Multi-Systemic Model of Juvenile Justice Reform

Table 3: Base Case Benefits for Year 5 and Net Present Value Over Implementation Period

\begin{tabular}{|c|c|c|c|}
\hline Group & Description of Benefit & Year 5 & NPV over 5 years \\
\hline CA Taxpayers & Avoided incarceration costs & $\$ 8,821,532$ & $\$ 168,810,263$ \\
\hline & Avoided arrest costs & $\$ 6,365$ & $\$ 121,798$ \\
\hline & Returns to increased education & $\$ 3,204,365$ & $\$ 61,576,592$ \\
\hline & Total & $\$ 12,032,262$ & $\$ 230,508,653$ \\
\hline Youth Offenders & Increased future earnings & $\$ 53,406,080$ & $\$ 1,026,276,539$ \\
\hline & Avoided sexual assault & $\$ 22,969,520$ & $\$ 99,446,001$ \\
\hline Total & $\$ 76,375,600$ & $\$ 1,125,722,540$ \\
\hline $\begin{array}{c}\text { Future Crime } \\
\text { Victims }\end{array}$ & Cost of crime prevented & $\$ 295,874,669$ & $\$ 5,661,905,716$ \\
\hline Total NPV benefits & & $\$ 384,282,530$ & $\mathbf{\$ 7 , 0 1 8 , 1 3 6 , 9 1 0}$ \\
\hline
\end{tabular}

Note: Author's calculations.

the assumptions, sensitivity analysis more importantly draws out the important categories to consider when deciding whether to implement the policy intervention.

The importance of an actual decrease in recidivism rate was highlighted in the sensitivity analysis for this study. This section tested if the net benefit of $\$ 5.9$ billion in the base case held up in the best-case and worst-case scenarios. To do so, this analysis changed the rate of recidivism, capital costs, and the cost of incarceration in the current system.

\section{Best-Case Scenario}

Within a best-case scenario, calculations are changed to reflect the policy intervention exceeding the assumed effectiveness calculated in the earlier part of this article. The measurements changed were the number of facilities (and subsequently staff and capital costs), land costs associated with the facilities, current costs of confinement, the marginal tax rate of the increased lifetime earnings, and the decrease of recidivism rate. These variables were chosen because they have a wide range of values. Land costs widely vary depending on location within the state, so this sensitivity analysis assumed the smallest amount in order to create a best-case scenario cost. The current costs of confinement were changed because these costs also have a large range, which would impact the potential costs avoided. One of the benefits to taxpayers is the assumed marginal tax revenue for the state, and therefore, in this scenario, the marginal tax rate was changed in order to increase the potential revenue. The recidivism rate is a key assumption, so it was decreased to test for a larger impact. The variable values were also changed because of the degree the assumptions made about their values impact the overall calculations including recidivism rates. These values were changed using the lowest reasonable costs and best estimate of outcomes. The best-case scenario resulted in a net benefit of $\$ 14.8$ billion as shown in Table 5 .

\section{Worst-Case Scenario}

In a worst-case scenario, calculations reflect the policy intervention not meeting the assumed effectiveness levels calculated earlier in the analysis. This analysis was based on the worst of the possible range of values for all of the major variables. The four variables this analysis changed were the recidivism rate, land costs connected to facilities, number of years youth are expected to be in the labor force (and subsequently the amount of increased earnings and tax revenue), and current costs of confinement. These variables were chosen because they range in value or because they are a critical part of the assumption. Land costs widely vary 
Table 4: Base Case Net Benefits Net Present Value Over Implementation Period

\begin{tabular}{|c|c|c|c|}
\hline Group & Benefits & Costs & Net Benefits \\
\hline CA Taxpayers & $\$ 230,508,653$ & $\$ 1,126,461,276$ & $-\$ 895,952,623$ \\
\hline Youth Offenders & $\$ 1,125,722,540$ & & $\$ 1,125,722,540$ \\
\hline Staff & & $\$ 5,407,447$ & $-\$ 5,407,447$ \\
\hline $\begin{array}{c}\text { Future Crime } \\
\text { Victims }\end{array}$ & $\$ 5,661,905,716$ & & $\$ 5,661,905,716$ \\
\hline $\begin{array}{c}\text { Total NPV } \\
\text { benefits }\end{array}$ & $\$ 7,018,136,910$ & $\$ 1,131,868,723$ & $\mathbf{\$ 5 , 8 8 6 , 2 6 8 , 1 8 7}$ \\
\hline
\end{tabular}

Note: Author's calculations.

depending on location within the state, so this sensitivity analysis assumed the highest cost in order to create a worst-case scenario cost. The current costs of confinement were changed since they too have a large range, and they impact the potential costs avoided. One of the benefits to taxpayers is the assumed marginal tax revenue for the state and, therefore, in this scenario the number of years assumed a youth would work was changed in order to decrease the potential revenue. The recidivism rate is a key assumption, and it was therefore increased to test whether or not the policy would still gain benefits with a smaller impact on youth outcomes.

The worst-case scenario resulted in a net benefit of $\$ 1.5$ billion as shown in Table 6. As expected, lowering the impact on recidivism drastically impacted the benefits accrued as most are tied to costs avoided due to a lower recidivism rate.

Table 5: Best-Case Scenario

\begin{tabular}{|c|c|c|c|}
\hline Group & Benefits & Costs & Net Benefits \\
\hline CA Taxpayers & $\$ 2,148,156,286$ & $\$ 837,989,901$ & $\$ 1,310,166,385$ \\
\hline Youth Offenders & $\$ 1,127,700,615$ & & $\$ 1,127,700,615$ \\
\hline Staff & & $\$ 3,314,241$ & $-\$ 3,314,241$ \\
\hline $\begin{array}{c}\text { Future Crime } \\
\text { Victims }\end{array}$ & $\$ 12,354,175,306$ & & $\$ 12,354,175,306$ \\
\hline $\begin{array}{c}\text { Total NPV } \\
\text { benefits }\end{array}$ & $\$ 15,630,032,207$ & $\$ 841,304,143$ & $\mathbf{\$ 1 4 , 7 8 8 , 7 2 8 , 0 6 5}$ \\
\hline
\end{tabular}

Note: Author's calculations.

\section{Considerations}

There were several limitations in this analysis. First, the assumption of uniform statewide distribution may impact both recidivism and costs. A central element of the program model is keeping youth close to home and, in a state as large as California, this may translate to 100 miles from home instead of Missouri's cap of 30 miles away from home. The variation in geographic placement will also impact costs as land values vary considerably across the state, although the sensitivity analysis attempted to address this variation.

Second, there is already a reform process underway in California that has substantial political support. California Governor Jerry Brown recently began juvenile justice reform by decentralizing state juvenile justice services. Advocates, correctional officers, and parents of offenders are rallying around this effort, and they are asking for further reform in a more systemic way (Goldstein 2012). While the Missouri Model could be part of that broader 
- Multi-Systemic Model of Juvenile Justice Reform

Table 6: Worst-Case Scenario

\begin{tabular}{|c|c|c|c|}
\hline Group & Benefits & Costs & Net Benefits \\
\hline CA Taxpayers & $\$ 34,236,972$ & $\$ 1,153,349,901$ & $-\$ 1,119,112,929$ \\
\hline Youth Offenders & $\$ 870,647,872$ & & $\$ 870,647,872$ \\
\hline Staff & & $\$ 5,407,447$ & $-\$ 5,407,447$ \\
\hline $\begin{array}{c}\text { Future Crime } \\
\text { Victims }\end{array}$ & $\$ 1,717,603,017$ & & $\$ 1,717,603,017$ \\
\hline $\begin{array}{c}\text { Total NPV } \\
\text { benefits }\end{array}$ & $\$ 2,622,487,861$ & & $\mathbf{\$ 1 , 4 6 3 , 7 3 0 , 5 1 3}$ \\
\hline
\end{tabular}

Note: Author's calculations.

reform, the required start-up costs are likely to present a major barrier.

Recently, Governor Brown called for a closure of the state's Division of Juvenile Justice (San Francisco Gate Newspaper 2012), which has led some to wonder about the long-term impacts within the California Department of Corrections and Rehabilitation. This move has the potential to strengthen and support the notion of localized services, but it also has the potential of removing a targeted agency for juveniles at the state level that could result in moving youth offenders into the adult system. The motivation behind the decision is related to both a state deficit and to an appreciation for the need for reform. The budget concern can become a major obstacle for approval of the expensive undertaking of implementing the MST model in California.

\section{Conclusion}

It is important to remember that a cost-benefit analysis is a rough estimate of costs and benefits forecast and monetized through reasonable calculations. Basing this study on assumptions, it is likely that there are costs and benefits that were not captured. The findings of this analysis indicate that, given the positive net benefits associated with the policy intervention, the implementation of the MST design for the state of California is promising. The total net benefits for the base case are $\$ 5.9$ billion. Although the worst-case scenario resulted in a substantial decrease of benefits, it still produced a net benefit of $\$ 1.5$ billion. It is important to note that the worst- case scenario considered some major outcome changes that are unlikely, such as building facilities on only the most expensive land. Therefore, one could be quite confident that the program will have greater benefits than costs based on the worst-case calculations of this study.

The key indicator of positive benefits is lowering the recidivism rate. It is crucial that the MST facilities stay capped in the range of 36 to 60 residents in order to ensure an intimate and effective program. One strategy to cut costs is to have experts from Missouri train the current California staff and CDCR leadership. Another way to avoid costs is to consider beginning building facilities and implementing the new programming process on a rolling basis. This approach would require a capital investment up front while continuing to pay for the current facilities, so the option could be met with political opposition. Gradual implementation would create the highest level of benefits, political and monetized, if it first targets areas with the largest populations of convicted high-risk youth offenders (places like Los Angeles County or San Francisco).

According to this analysis, the overall net benefits of implementing the MST model in California are positive. There are several groups that benefit from applying the MST model in California: California taxpayers reap financial benefits needed to address the considerably large state deficit, youth offenders receive the help they need and are placed on a path designed to help prevent further incarceration, and future victims are saved from the trauma and costs of juvenile crime. 


\section{References}

Act 4 Juvenile Justice. 2009. "Fact Sheet: Community-Based and Home-Based Alternatives to Incarceration.” Accessed March 27, 2013.

http://www.act4jj.org/media/factsheets/factsheet_59.pdf.

AECOM Construction Services. 2012. "New Beginnings Youth Development Center." Accessed February 14, 2012. http://www.aecom.com/What+We+Do/ Construction+Services/Market+Sectors/Government/_projectsList/New+Beg innings+Youth+Development+Center.

The Annie E. Casey Foundation. 2010. "The Missouri Model: Reinventing the Practice of Rehabilitating Youthful Offenders.” Accessed February 14, 2012. http:// www.aecf.org/MajorInitiatives/ /media/Pubs/Initiatives/Juvenile\%2oDetention\%20Alternatives\%20Initiative/MOModel/MO_Fullreport_webfinal.pdf.

The Annie E. Casey Foundation. 2011. "No Place for Kids: The Case for Reducing Juvenile Incarceration.” Accessed February 3, 2012. http://www.aecf.org/OurWork/JuvenileJustice/ /media/Pubs/Topics/Juvenile\%20Justice/Detention\%20Reform/NoPlaceForKids/JJ_NoPlaceForKids_Full.pdf.

Bureau of Justice Statistics. 2010. "Sexual Victimization in Juvenile Facilities Reported by Youth, 2008-2009.” Accessed April 19, 2012. http://bjs.ojp.usdoj.gov/content/pub/pdf/svjfryo9.pdf.

Bureau of Labor Statistics. 2011. "Occupational Employment and Wages. May 2011. Secondary School Teachers, Expect Special and Career/Technical Education.” Accessed March 15, 2013.

http://www.bls.gov/oes/current/oes252031.htm.

-_- . 2012a. "Household Data Annual Averages. Median weekly earnings or full-time wage and salary workers by detailed occupation.” Accessed March 15, 2013. http://www.bls.gov/cps/cpsaat39.pdf.

- - . 2012b. "Occupational Outlook Handbook, Correctional Officers." Accessed March 15, 2013.

http://www.bls.gov/ooh/protective-service/correctional-officers.htm.

-_-. 2012c. "Occupational Outlook Handbook. Probation Officers and Correctional Treatment Specialists.” Accessed (March 15, 2013).

http://www.bls.gov/ooh/community-and-social-service/probation-officersand-correctional-treatment-specialists.htm\#tab-5 .

- - . 2012d. "Employer Costs for Employee Compensation news release text." Accessed March 7, 2013. http://www.bls.gov/news.release/ecec.nro.htm.

-—-. 2012e. "Occupational Outlook Handbook. Psychologists.” Accessed

March 15, 2013.

http://www.bls.gov/ooh/Life-Physical-and-Social-Science/Psychologists.htm.

-- . 2012f. "Occupational Outlook Handbook, Social Workers.” Accessed March 15, 2013. http://www.bls.gov/ooh/Community-and-Social-Service/Social-work ers.htm\#tab-5.

-_-. 2013a. "Usual Weekly Earning Summary.” Accessed March 28, 2013. http:// www.bls.gov/news.release/wkyeng.nro.htm.

- - . 2013b. "U.S. Department of Labor, Occupational Outlook Handbook, 2012-13 Edition, Top Executives.” Accessed April 5, 2013. http://www.bls.gov/ooh/ management/top-executives.htm.

CDCR (California Department of Corrections and Rehabilitation). 2008. "Youth Population Overview.” Accessed February 3, 2012. http://www.cdcr.ca.gov/Juve- 
nile_Justice/DJJ_Quick_Facts/Youth_Population_Overview.html.

-—-. 2009a. "Population Overview." Accessed March 7, 2013. http://www.cdcr. ca.gov/Reports_Research/docs/research/POPOVER2009.pdf.

-—-. 2009b. "DJJ Quick Facts.” Accessed February 3, 2012. http://www.cdcr.ca.gov/ Juvenile_Justice/DJJ_Quick_Facts/Youth_Population_Breakdown.html.

-—-. 2010a. "Population Overview." Accessed March 7, 2013. http://www.cdcr. ca.gov/Reports_Research/docs/research/POPOVER2010.pdf.

-—-. 2013a. "About DJJ."

Accessed March 7, 2013. http://www.cdcr.ca.gov/Juvenile_Justice/About_ DJJ/index.html.

--—. 2013b. "DJJ Facility Locations.” Accessed March 7, 2013. http://www.cdcr. ca.gov/Juvenile_Justice/Facility_Locations/index.html.

-—-. 2013c. "Frequently Asked Questions." Accessed March 7, 2013. http://www. cdcr.ca.gov/Juvenile_Justice/FAQs_About_DJJ/index.html.

-—-. 2010b. "Juvenile Justice Outcome Evaluation Report. Youth Released from the Division of Juvenile Justice in Fiscal Year 2004-2005.” Published August 16, 2010. Accessed January 26, 2012. http://www.cdcr.ca.gov/Reports_Research/ docs/Recidivism\%20Report.FY0405.\%20FINAL.DJJ.pdf.

California Department of Justice. 2009. "Criminal Justice Fiscal Year Expenditures by type of Agency.” Accessed April 26, 2012. http://stats.doj.ca.gov/cjsc_stats/ profo9/00/10.htm.

Cellini, Stephanie. 2012. "Benefit-Cost Analysis." The George Washington University. Washington, D.C.

Center for Children's Law and Policy. 2010. "Understanding the BJS Study of Sexual Victimization in Juvenile Facilities.” Accessed March 11, 2013.

http://www.cclp.org/documents/Conditions/Fact\%20Sheet\%20--\%20 2010\%20BJS\%20Sexual\%20Victimization\%20Study.pdf.

CBKB (Cost Benefit Knowledge Bank for Criminal Justice). 2012. "Victim Costs." Accessed April 19, 2012. http://cbkb.org/toolkit/victim-costs/.

-—-. 2013. "Discounting." Accessed March 11, 2013. http://cbkb.org/toolkit/discount ing/.

DCDYRSF (District of Columbia Department of Youth Rehabilitation Services Facilities). 2012. "New Beginnings Youth Development Center." Accessed February 14, 2012. http://dc.gov/DC/DYRS/Youth+Services/DYRS+Facilities/New+Be ginnings+Youth+Development+Center.

Donner, Debbie. 2012. "The impact of Prisons on Property Values." eHow, accessed April 27, 2012. http://www.ehow.com/facts_6937936_impact-prisons-property-value.html.

Feld, Barry C. 1999. Bad Kids: Race and the Transformation of the Juvenile Court. New York: Oxford University Press.

Goldstein, Brian. 2012. "Still, a Promise of Reform for California's Juvenile Justice System." Accessed March 7, 2013.

http://jjie.org/still-promise-of-reform-for-californias-juvenile-justice-system/90471.

Justice Policy Institute. 2009. “The Costs of Confinement: Why Good Juvenile Justice Policies Make Good Fiscal Sense.” Accessed January 26, 2012. http://www.justicepolicy.org/uploads/justicepolicy/documents/o9_05_rep_costsofconfinement_jj_ps.pdf.

- - . 2006. "The Dangers of Detention: The impact of Incarcerating Youth in Detention and Other Secure Facilities." Accessed March 28, 2013. 
http://www.justicepolicy.org/uploads/justicepolicy/documents/dangers_of_ detention.pdf.

Krisberg, Barry. 2005. Juvenile Justice: Redeeming Our Children. California:

Sage Publications, Inc.

- - . 2009. "Evaluation of the Enhanced Ranch Program: Santa Clara County Probation Department." Accessed March 27, 2013. http://www.library.ca.gov/ crb/o9/SantaClara.pdf.

LandWatch. 2013. Land and Rural Retreats, United States, California, 11-12 acres, Land. Accessed March 28, 2013. http://www.landwatch.com/default.aspx?ct=R\&typ $\mathrm{e}=5,30 ; 13,12 ; 268,6843 \&=\& \mathrm{r} . \mathrm{PSIZ}=11 \% 2 \mathrm{c} 12 \& \mathrm{pg}=1$.

Latessa, E. and Lovins, B. 2010. The Role of Offender Risk Assessment: A Policy Maker Guide.

Legislative Analyst's Office. 1995. "Juvenile Crime- Outlook for California: How does California’s Juvenile Justice System work?” Accessed January 22, 2012. http:// www.lao.ca.gov/1995/050195_juv_crime/kkpart5.aspx.

Lipsey, M. Howell, J. Kelly, M. Chapman, G. Carver, D. 2010. Improving the Effectiveness of Juvenile Justice Programs. Center for Juvenile Justice Reform. District of Columbia: Georgetown University.

Mendel, Dick. 2010. "In Juvenile Justice Care, Boys Get Worse: Growing evidence says juvenile systems exacerbate delinquency.” Accessed March 28, 2013.http:// www.aecf.org/MajorInitiatives/JuvenileDetentionAlternativesInitiative/Resources/May1onewsletter/CloserLook2.aspx.

NDTAC (National Evaluation and Technical Assistance Center for the Education of Children and Youth Who Are Neglected, Delinquent, or At-Risk). n.d. (a). "State and National Fast Facts California. Accessed March 13, 2013.

http://data.neglected-delinquent.org/index.php?id=01\&state=California\&fi $\mathrm{ps}=6$.

- - . n.d. (b). "State and National Fast Facts Missouri. Accessed March 13, 2013. http://data.neglected-delinquent.org/index.php?id=01\&state=Missouri\&fi $\mathrm{ps}=29$.

-—- n.d.(c). "National Fast Facts. Accessed March 13, 2013. http://data.neglecteddelinquent.org/index.php?id=01.

Office of Juvenile Justice and Delinquency Prevention. 2002. "Cost-Benefit Analysis for Juvenile Justice Programs.” Accessed February 3, 2012. http://www.jrsa.org/ njjec/publications/cost-benefit.pdf.

-—-. 2013. "Correctional Facilities.” Accessed March 11, 2013. http://www.ojjdp.gov/ mpg/progTypesCorrectional.aspx.

Reed Construction. 2013. "Prison Information”. Accessed March 11, 2013. http://www.reedconstructiondata.com/building-types/prisons/california/.

San Francisco Gate Newspaper. 2012. "Plan to end juvenile justice division faces fight." Accessed April 30, 2012.

http://www.sfgate.com/cgi-bin/article.cgi?f=/c/a/2012/02/20/BA311N818B. DTL.

Vestal, Christine. 2008. "States Adopt Missouri Youth Justice Model.” Accessed March 16, 2013. http://www.pewstates.org/projects/stateline/headlines/statesadopt-missouri-youth-justice-model-85899387354.

Washington State Institute for Public Policy. 2001. The Comparative Costs and Benefits of Programs to Reduce Crime. Olympia, WA: The Evergreen State College. 
Ana Gioconda Jara is a second year Masters of Public Policy student at The George Washington University, concentrating in social policy with an emphasis in juvenile justice. She earned a BA in sociology and women's studies from the University of California, Los Angeles. She has years of community and youth development experience and intends to focus her life's work in reforming juvenile justice policy for marginalized youth populations.

The author would like to thank Josette Arevalo, Anne Berry, Michael Holzer and Kristin Hubing for their patience and diligent editing of this paper. She would also like to thank Dr. Stephanie Cellini for her introduction and encouragement to pursue the topic of cost-benefit analysis, and Dr. Donna Infeld for her comments and guidance throughout the editing process. The author thanks Josette Arevalo and Kristin Hubing for their encouragement and guidance during the writing of this article. The author would also like to thank all her friends and family who repeatedly focused her on the end goal of publication: Gracias Madre y Kristina! Special thanks to The Florida House for strengthening me, Anamita, Ashley and Sonia you are great friends. 